These figures suggest that the effects of chlorpromazine and 2,4-dinitroorthocresol are additive. R. J. GARNER* Inge Marre Skude Department of Pharmacology and Toxicology, Royal Veterinary and Agricultural College, Copenhagen. Oct. 2.

- Present address: Veterinary Laboratory, University, Bristol. ${ }^{1}$ Berger, M., Strecker, H. J., and Waelsch, H., Nature, 17\%, 1234 (1956).

\section{Antibody Formation by Protein Components of Bee Venom}

IT is not yet known for certain whether the physiological responses to bee venom include the formation of antibodies. Earlier investigators have obtained divergent results when investigating immunization against different effects of the venom. This is probably in part due to the fact that a series of pharmacological and enzymatic reactions are caused by quite different constituents of the venom ${ }^{1}$. In recent years, several proteins with various biological properties have been isolated: first, the pharmacologically highly active toxin-fraction (so-called 'fraction $\left.\mathrm{I}^{\prime}\right)^{2}$; then the enzymes phospholipase $A^{3}$ and hyaluronidase ${ }^{4}$, which on electrophoresis migrate in the so-called 'fraction II'. From these findings arises the question whether antigenie properties may be found with these substances.

Solutions of cautiously dried bee venom were injected intravenously into rabbits at intervals of one to two weeks. Before every injection samples of serum were obtained and stored at $-6^{\circ}$ to $-8^{\circ} \mathrm{C}$. Repeated doses of 0.2 or $1.0 \mathrm{mgm} . / \mathrm{kgm}$. caused increasing formation of antiphospholipase and antihyaluronidase in the sera (cf. Fig. 1). On the other hand, the effects of bee venom on the isolated guinea pig auricle or frog heart, the frog sartorius, guinea pig gut or uterus, and also its systemic toxicity in white mice and the (direct) hæmolysis of human erythrocytes by fraction $\mathrm{I}$, were not diminished by the sera of the immunized rabbits to a greater degree than they were by normal rabbit serum.

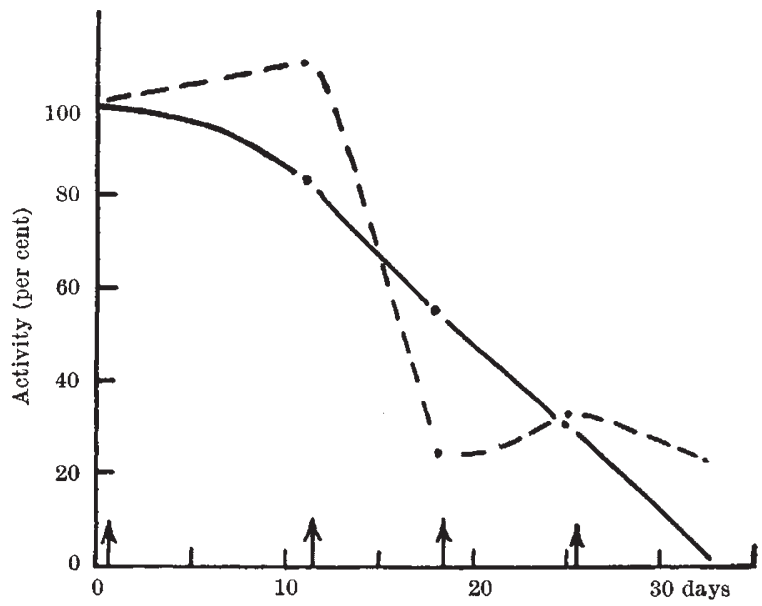
Fig. 1. Increase of antiphospholipase and antihyaluronidase bee venom. At arrows: $1 \mathrm{mgm}$./kgm. bee venom. Activity is given as a percentage of the activity of a control (venom + stored normal serum). - - hyaluronidase (ref. 5) ; venom, $1: 20,000$ serum, 1:40, . $1: 336,000$, serum, $1: 42$ (ref. 5); venom,
The experiments show that two enzymesphospholipase $A$ and hyaluronidase-of bee venom give rise to immunization, whereas the non-enzymatic but pharmacologically highly active toxin-fraction I seems to be non-antigenic.

The investigations will be extended, and a detailed description of methods and results will be published in the dissertation of one of us (EI K.).

ERNST HABERMANN

Mahmoud M. A. El Karemi

Pharmakologisches Institut,

Universität, Würzburg. Aug. 2.

'Neumann, W., Naturwiss., 41, 322 (1954).

${ }^{2}$ Neumann, W., Habermann, E., and Amend, G., Naturwiss., 39, 286 (1952), Neumann, W., and Habermann, E., Arch. 'Exp. Path. u. Pharmakol., 222, 367 (1954). Fischer, H. G., and Neumann, W. P., Biockem. Z., 324, 447 (1953).

${ }^{3}$ Habermann, E., Neumann, W. P., and Neumann, W., Naturwiss.,

Habermann, E., Biochem. $\boldsymbol{Z}$. (in the press)

${ }^{5}$ Neumann, W. P., and Habermann, E., Biochem. Z., 327, 170 (1955).

\section{Formation of Erythulose from Hydroxypyru- vate in the Presence of Yeast Carboxylase}

Hydroxypyruvate is a metabolite which can arise from the biological oxidation of glycerate $\theta^{1}$, transamination of serin $\theta^{2}$, or decarboxylative condensation of glyoxylate ${ }^{3}$. In the presence of cocarboxylase, magnesium ions and transketolase, it yields 'active' (cocarboxylase-bound) glycolaldehyde, capable of forming a ketopentose 5-phosphate with D-glyceraldehyde 3-phosphate ${ }^{4,5}$ or sedoheptulose 7-phosphate with D-ribose 5-phosphate ${ }^{5,6}$. Transketolase decarboxylates hydroxypyruvate only when a suitable acceptor aldehyde is present ${ }^{\bar{D}}$ (acetaldehyde will not. serve $^{7}$ ) and does not decarboxylate pyruvate ${ }^{5,7}$. Crude yeast pyruvate carboxylase, on the other hand, has been stated not to decarboxylate hydroxypyruvate ${ }^{8}$

The conclusions of Akabori et al. ${ }^{9}$ that muscle minces cause a decarboxylative acetoin type of condensation of dihydroxyfumaric acid, leading by way of a hydroxypyruvate intermediate to the formation of tetrose and hexose sugars, led us to re-investigate the action of partially purified yeast carboxylase, prepared from several varieties of yeast, on pure lithium hydroxypyruvate ${ }^{1}$. Contrary to the experience of Meister ${ }^{8}$, we observed a slow steady decarboxylation at $p \mathrm{H} 5$, and this became vigorous at $p H \quad 6 \cdot 5$. Colorimetric estimation ${ }^{1}$ confirmed the disappearance of hydroxypyruvate, with little or no formation of free glycolaldehyde. A neutral reducing substance accumulated in good yield, having $R_{F}$ on paper chromatographic analysis in phenol/water of $0 \cdot 695$, identical with that of pure L-erythulose and distinct from that of erythrose $\left(R_{F}=0 \cdot 65\right)$. This enzymically synthesized tetrose gave a crystalline 0 -nitrophenylhydrazone (found $\mathrm{N}=16.5$ per cent, calc. 16.5 per cent), melting point $150^{\circ}$, unchanged on admixture with authentic erythulose o-nitiophenylhydrazone. Determination of the optical rotation in ethanol of this derivative gave $[\alpha]_{D}=$ $+48^{\circ} \pm 3^{\circ}$, thus characterizing the sugar as Lerythulose. 'The output of carbon dioxide in relation to the loss of hydroxypyruvate indicates the reaction to be :

$$
\begin{aligned}
& 2 \mathrm{CH}_{2} \mathrm{OH} . \mathrm{CO} . \mathrm{COOH} \\
& \mathrm{CH}_{2} \mathrm{OH} \cdot \mathrm{CO} \cdot \mathrm{CH}(\mathrm{OH}) \cdot \mathrm{CH}_{2} \mathrm{OH}+2 \mathrm{CO}_{2}
\end{aligned}
$$

